\title{
Mechanical performance of date palm fibre-reinforced gypsums
}

\author{
Wail N. Al-Rifaie ${ }^{1} \cdot$ Maamoon Al-Niami $^{2}$
}

Received: 13 March 2016/Accepted: 21 June 2016/Published online: 5 July 2016

(C) Springer International Publishing Switzerland 2016

\begin{abstract}
The present work examines the properties of gypsum reinforced with palm fibres, as a low-cost construction material. Panels of $500 \times 500 \times 20 / 25 \mathrm{~mm}$ were fabricated and tested for impact strength, compressive strength and flexural strength. The results are compared with those made from fibreglass-reinforced gypsum.
\end{abstract}

Keywords Gypsum · Fibreglass · Date palm fibre · Low cost

\section{Introduction}

Prefabricated gypsum boards are used frequently for interior bulkhead plain gypsum boards or those reinforced with fibreglass.

Gypsum plaster is widely used in building; mainly for coating interior surfaces. Although its compressive strength may be as high as $68.9 \mathrm{~N} / \mathrm{mm}^{2}$ at a low water/plaster ratio, it is comparatively weak in tension and has low impact

Committee C11 on Gypsum and Related Building Materials and Systems.

Wail N. Al-Rifaie

wnrifaie@yahoo.com

1 Philadelphia University, Amman, Jordan

2 University of Technology, Baghdad, Iraq strength [1]. Improvement could be achieved from the use of glass fibres as reinforcement.

There are two main methods of reinforcing gypsum with fibrous material. One method is to concentrate the fibres in the tensile zones of the resulting structural element so as to match the external tensile force and use the matrix to control buckling. The efficiency of this process increases with the fibre modulus.

The other method is to disperse glass fibres uniformly in the matrix so as to form a homogeneous mixture. Ideally, this results in an isotropic material and gives improved resistance to microcracking and crack propagation under service conditions.

Since the early 1970s, gypsum has been used in an E-glass fibre-reinforced form, especially in false ceilings and interior partitions.

Ali and Grimer [1] used commercially available E-glass fibres to reinforce a gypsum plaster matrix and produced a composite material having improved tensile and impact properties values.

Djoudi et al. [2] describe an investigation on the use of a new composite construction material composed of plaster, sand, crushed gravel and date palm fibres of waste agriculture peels, having mechanical properties potentially useful in technical domains. They concluded that the new composite construction material is a promising composite for saving energy suitable for renovation purposes.

Benmansour et al. [3] presented an investigation on the use of a new material, composed of natural cement, sand and date palm fibres. The main goal was to evaluate the possibility of using this new material as insulating building materials.

Date palm fibres were pulled out of what is called sheath in the palm tree and used in the present investigation to reinforce gypsum plaster (Fig. 1). 
Fig. 1 Sheath fibre from the leaf base as it comes from the palm (a) and in detail (b)
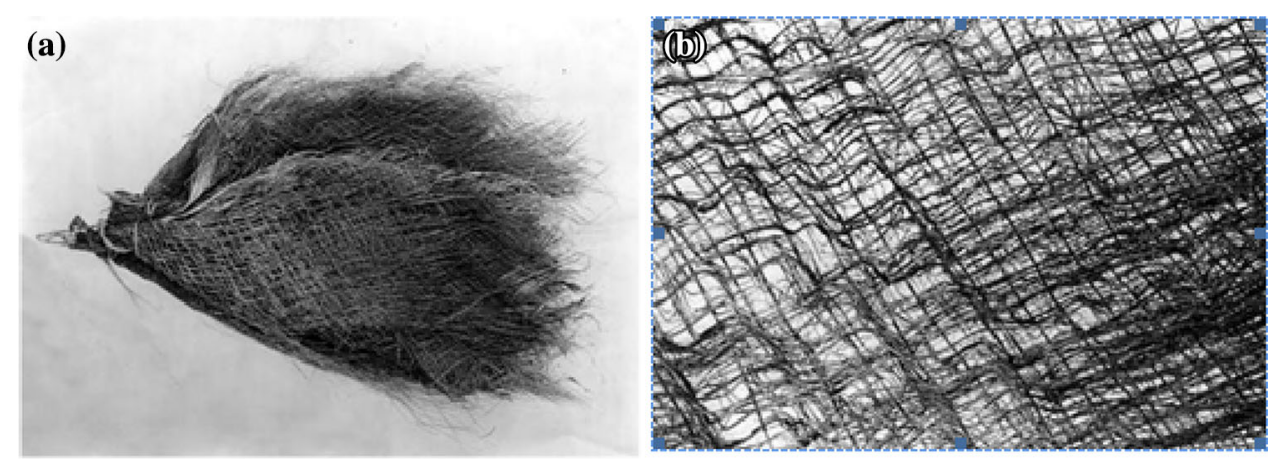

\section{Experimental work}

\section{Materials \\ Gypsum}

Plaster of Paris is used throughout the present investigation. The setting time for gypsum slurry was determined via trials on gypsum slurry of $54 \%$ water content at $24^{\circ} \mathrm{C}$. The average setting time was 9-11 min.

The gypsum was also chemically analysed and the percentages of the major content elements are given in Table 1.

\section{Reinforcing material (data palm fibre)}

Natural fibres were used to reinforce gypsum plaster, and date palm was used for this purpose. Date palm fibres are pulled out of what is called sheath in the palm tree, and it can be seen that new date palm leaves come out from a tender cover tissue, which upon growth of the leaf remains at its base attached to its lateral edges, and surrounding the trunk of the palm. The connective tissue disappears and a brownish fibrous sheath is left, which when pruning the leaves can be torn loose and is known under the name of leaf. The sheath (leaf) was then taken and spread into separate fibres with different diameters and lengths. These fibres were then scattered into the matrix (gypsum), to produce the composite finally. A simple tensile stress, using a fibre tensile test apparatus, was held on these fibres to determine its tensile strength. Several tests were made, and an average value of $64 \mathrm{~N} / \mathrm{mm}^{2}$ was obtained. Although fibres from several kinds of date palms were used, they all seemed to have the same properties. As known, these

Table 1 Chemical analysis for gypsum

\begin{tabular}{lc}
\hline $\mathrm{CaO}$ content $\%$ & 39.2 \\
$\mathrm{SO}_{3}$ content $\%$ & 51.52 \\
Water content $\%$ & 5.6 \\
Loss on ignition $\%$ & 4.96 \\
\hline
\end{tabular}

natural fibres have a good tendency to absorb water, so fibres used to reinforce gypsum were first soaked in water for 5 days to avoid lowering the percentage of water used to complete mixing after adding the fibres (see Table 2).

\section{Fabrication of composite sheets}

The test variables included changing each water/gypsum (w/g) ratio and fibre/plaster slurry ratio by weight. 40, 60 and $80 \%$ were applied for water/gypsum ratio, and $0,2,4$, $6,8,10 \%$ for fibre volume fraction.

Manual mixing of the slurry followed by manual compaction was considered. Precautions were taken to ensure homogeneity and full compaction.

Gypsum was first premixed with water setting out of the fibres in the ratios defined and then date palm fibres were added to the plaster slurry and mixed.

All mixing took place at $23{ }^{\circ} \mathrm{C}$ and tap water was used for mixing. No retarders or admixtures were used to adjust the setting time.

The $500 \times 500 \mathrm{~mm}$ mould was made of steel. The material was spread to a thickness of 20 or $25 \mathrm{~mm}$. The top surface was leveled and compacted to drive out the excess water. The sheets were kept in their moulds for $24 \mathrm{~h}$, followed by demoulding and air drying at $31{ }^{\circ} \mathrm{C}$ for 15 days before testing.

\section{Flexural strength test}

Specimens $50 \times 150 \mathrm{~mm}$ were cut from $20 \mathrm{~mm}$ thick sheet (Fig. 2) and tested under three-point loading at a span of $135 \mathrm{~mm}$ in an Instron testing machine. A constant cross head speed of $2.5 \mathrm{~mm} / \mathrm{min}$ was used.

Table 2 Typical properties of date palm fibres

\begin{tabular}{ll}
\hline Fibre length & $50-300 \mathrm{~mm}$ \\
Ultimate tensile strength & $55-67 \mathrm{~N} / \mathrm{mm}^{2}$ \\
Fibre diameter & $0.1-2 \mathrm{~mm}$ \\
Bulk density & $600-700 \mathrm{~kg} / \mathrm{m}^{2}$
\end{tabular}


Fig. 2 Specimen and test used to determine the flexure strength
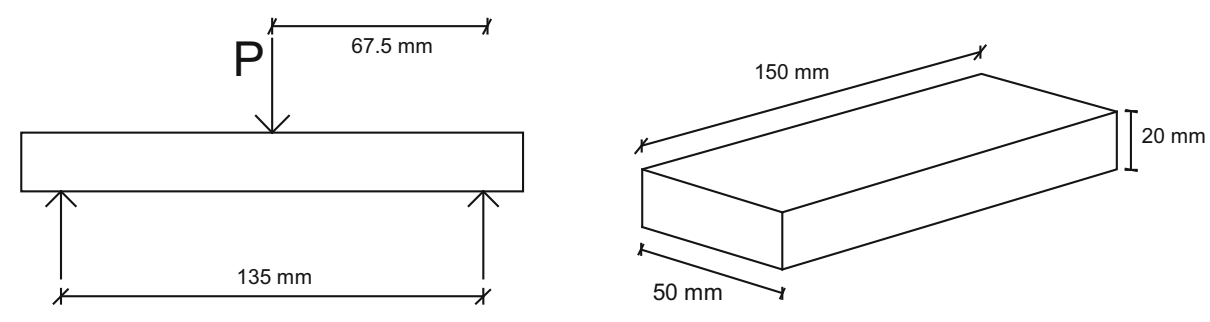
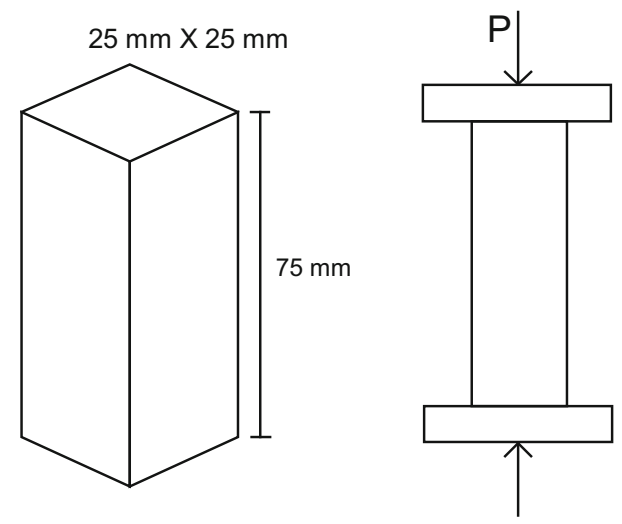

Fig. 3 Specimen and test used to determine the compression strength

\section{Compressive strength test}

Prisms of $25 \times 75 \mathrm{~mm}$ cut from the $25 \mathrm{~mm}$ thickness sheets (Fig. 3) were tested for the measurement of compressive strength. The ends of the specimens were capped with neat plaster and the ultimate failure loading recorded with an Instron testing machine. A constant cross head speed of $2.0 \mathrm{~mm} / \mathrm{min}$ was used for all compressive strength tests.

\section{Impact test}

A swinging pendulum Izod type impact tester was used to measure the impact strength on $10 \times 100 \mathrm{~mm}$ specimens cut from $25 \mathrm{~mm}$ sheet (Fig. 4) and no notch was made to the specimen considering this is an Izod-unnotched test method according to the ASTM standards un-notched specimen cut from the $25 \mathrm{~mm}$ sheet according to ASTM C11 [4]. With the specimen clamped at the base, the pendulum was released from a constant height and its movement after the impact recorded on a calibrated scale. This reading gave the amount of energy absorbed in breaking the specimen at a particular cross-sectional area.

\section{Density measurement}

Specimens $50 \times 50 \mathrm{~mm}$ were cut from the $20 \mathrm{~mm}$ sheet dried at $40{ }^{\circ} \mathrm{C}$ for $24 \mathrm{~h}$. The dry weight was determined and the specimens were waterproofed by applying a thin

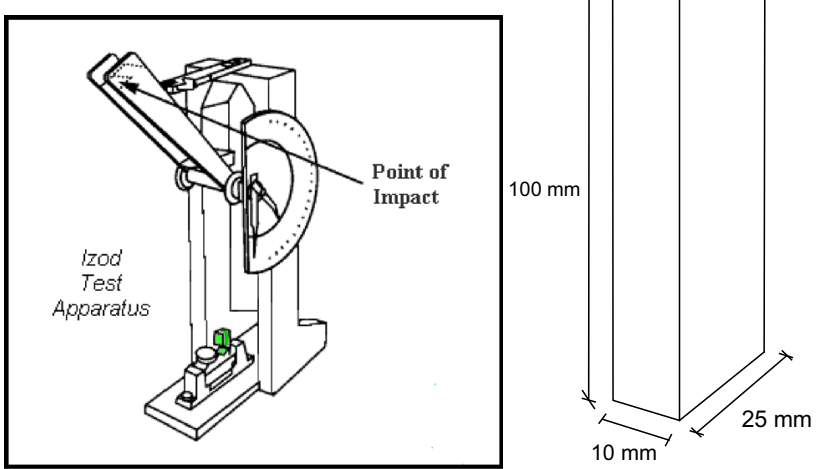

Fig. 4 Specimen and apparatus used to determine the impact strength

coating of grease. Their volume was then determined by weighing in water.

\section{Results}

Figure 5 shows the relationship between the compression strength and palm fibre content for three specific percentages of $(w / g)$ ratio.

\section{Flexural strength results}

Each value of flexural strength recorded is the average of six tested specimens for each composite parameter. The following equation was used and the values were then plotted as in Fig. 6.

$\sigma_{\mathrm{fu}}=3 / 2 \frac{P L}{b h^{2}}$,

where $\sigma_{\mathrm{fu}}$ is the modulus of rupture, $\mathrm{N} / \mathrm{mm}^{2} ; P$ the load, $\mathrm{N} ; L$ the test length of the specimen, $\mathrm{mm} ; b$ the section width for the specimen, $\mathrm{mm}$; and $h$ the depth of the specimens, $\mathrm{mm}$.

This calculation was based on an assumption of elastic behaviour for the composite material through the entire time of test.

Two more factors were studied for the composites flexural strength, depending on the specimen's position in 
Fig. 5 Relationship between compressive strength and palm content

Fig. 6 Relationship between modulus of rupture and palm fibre content modulus of rupture and palm fibre content
Fig. 7 Relationship between
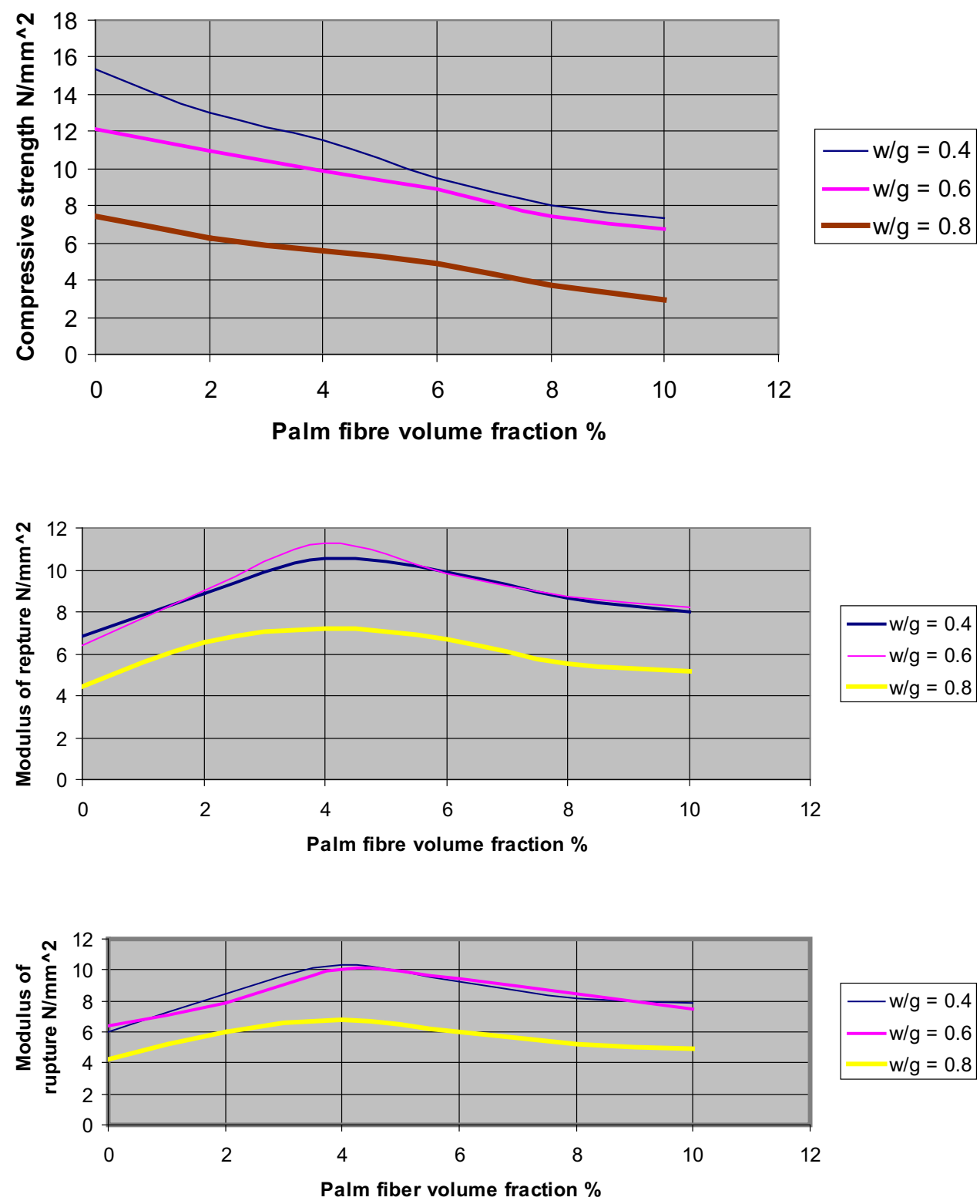

the composite. The first factor concerned the face of the specimen stressed in tension: Two levels were taken: the lower surface adjacent to the mould and the free surface as fabricated. The values are plotted as shown in Fig. 7.

The second factor was the position of the specimens in the sheet, using two levels: the inside half remote from the edge and the outside half adjacent to the edge. Figure 8 shows the calculated results for the latter case.

\section{Discussion}

In the present investigation, composites of gypsum plaster and palm fibre were made, and two parameters were considered: water/gypsum ratio using 40,60 and $80 \%$, and palm fibre volume fraction, using $0,2,4,6,8 \%$, and $10 \%$.
When fabricating these composite sheets, the major practical problem was the flocculation of fibres during mixing due to the relatively high fibre lengths. This yielded a nonhomogeneous mixture, so a manual method was then adopted (see Figs. 9, 10).

Evaluation of workability was made by visual observations during mixing and placing.

It was clear that workability decreased with increasing fibre loading and decreasing water/gypsum ratio, especially when using a volume fraction of fibres larger than $60 \%$ and a water/gypsum percentage of $40 \%$. The hardened composite sheets were cut to obtain specimens needed for testing, using a very slim electric saw to ensure clean and straight faces of the specimens.

From the relation between the modulus of rupture and palm fibre content, it is evident that the strength of the 
Fig. 8 Relationship between modulus of rupture and palm fibre content
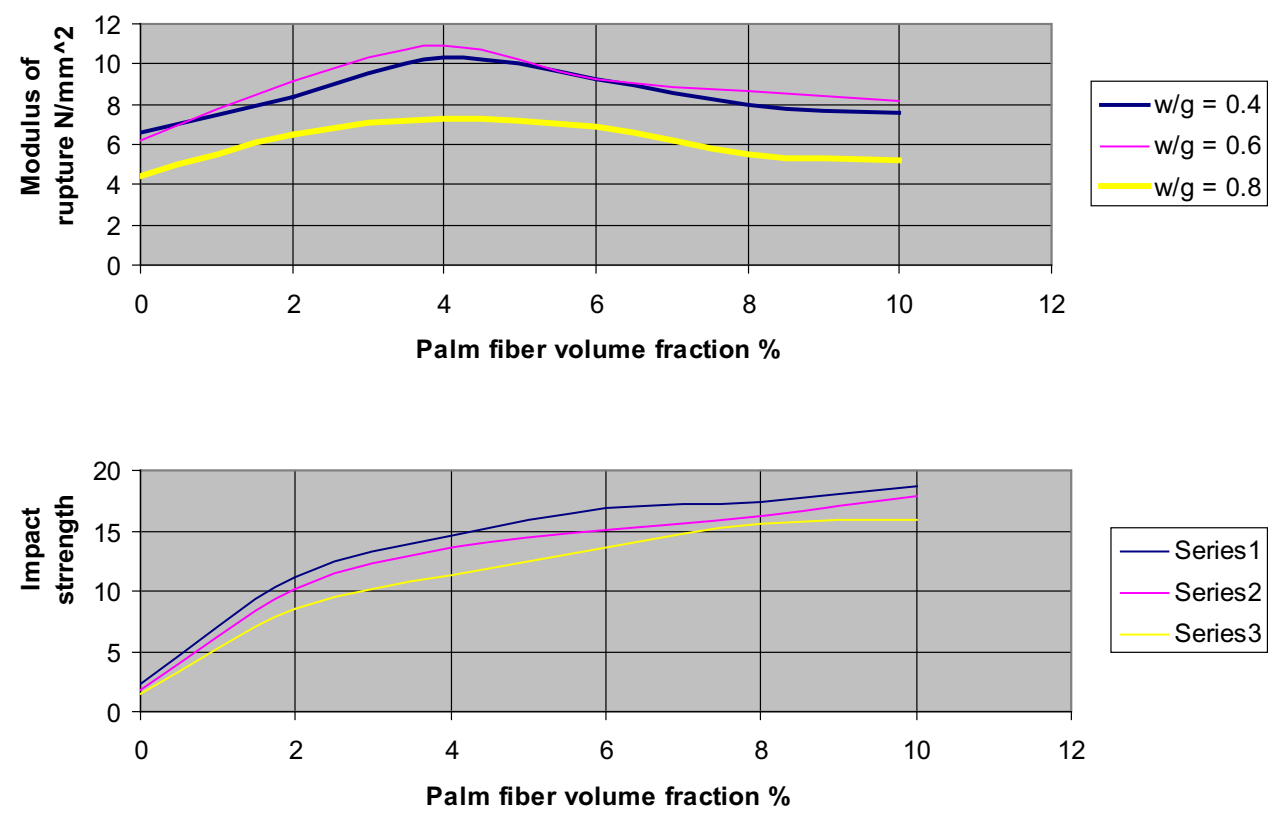

Fig. 9 Relationship between impact strength and palm fibre content

Fig. 10 Relationship between density and palm fibre content

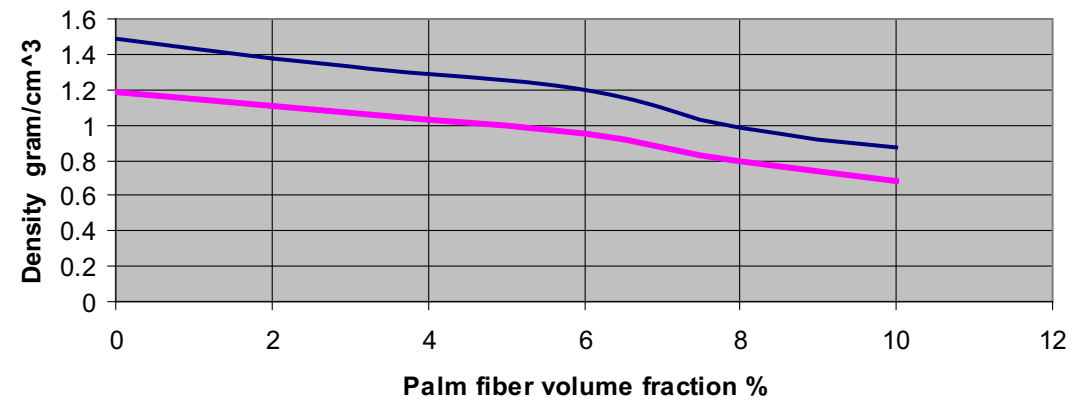

composite reached a maximum value at $4 \%$ palm fibre content for all changing water/gypsum content, and then decreased. This drop in strength of the matrix was due to decrease in the density and compressive strength of the matrix with increasing palm fibre content, as dictated by the present fabrication technique.

When applying flexural load to such composites, the materials exhibit two damage phases, the first is the matrix failure and the second is either fibre breakage or fibre pullout of the matrix. The latter phenomenon was more noticeable when using short fibre lengths.

The palm fibre composites tended to exhibit fibre breakage for the lengths used, which appeared to be above the critical length for this combination of materials.

The effect of increasing water/gypsum ratio is shown in Fig. 11 for both reinforced and neat gypsum. It is obvious how flexural strength for the latter drops by increasing water content, while for the reinforced gypsum at $4 \%$ fibre content the composite reaches its highest value at $60 \%$ $\mathrm{w} / \mathrm{g}$. This is because the workability for mixing gypsum at
$40 \% \mathrm{w} / \mathrm{g}$ was lower than that for $60 \% \mathrm{w} / \mathrm{g}$, resulting in a better property composite.

In contrast to the modulus of rupture, the compressive strength decreased with increasing palm fibre content. This was due to the reduction in density of the composite resulting from manual compaction. This may be particularly important at low water/gypsum ratios where workability can be low and low pressure processing may not be feasible. Overall, increasing the effect of water content in the mixture decreased the compressive strength for composites and neat gypsum; see Fig. 12.

The impact strength showed by far the highest improvement with increasing palm fibre content and reached eight to ten times the value for neat gypsum at palm fibre contents of $8 \%$.

The increase is due to the crack-arresting mechanism provided by the incorporation of fibres. Cracks originating in the highly stressed tensile zone of the matrix propagate on reaching the fibre and deflect along the weak interface of the matrix and fibre. 
Fig. 11 The effect of increasing water/gypsum ratio on flexural strength for both reinforced and neat plaster
Fig. 12 The effect of increasing water/gypsum ratio on compressive strength for both reinforced and neat plaster
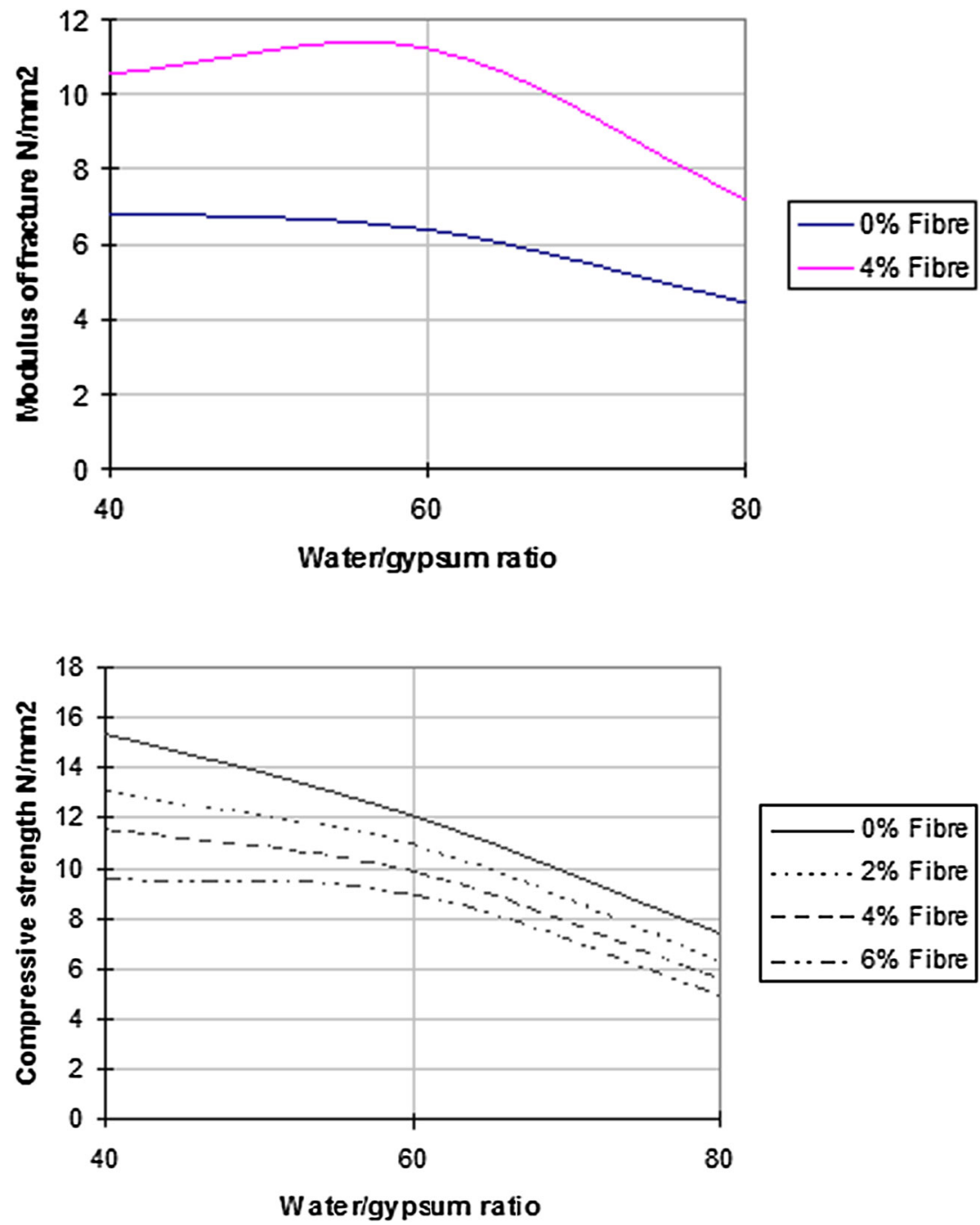

Thus, the energy of the impact or fracture is dissipated along the fibre-matrix interface and the fibres are pulled out. Paradoxically, it is evident that low bond strength is an advantage as far as impact resistance is concerned.

Improvement of the bond between plaster and glass fibre by compaction will decrease the amount of crack growth along the interface and so decrease the amount of energy absorbed by this mechanism with consequent reduction in impact strength. However, some limited additional tests using fibreglass-reinforced gypsum confirmed that increase in density of $10 \%$ obtained by improved compaction did in fact lead to a reduction of up to 20-25\% in impact values.

The density versus palm fibre content relation shows an immediate decrease in density with increasing fibre content, because palm fibres are of low density compared to gypsum plaster. At higher fibre content, the insufficient compaction achieved by the technique induces voids in the resulting material. This reduction in density is advantageous for impact strength, but disadvantageous for flexural strength. It might be required to strike a compromise between these factors to achieve a product having the desired properties.

\section{Conclusions}

The visibility of using date palm fibres in gypsum board is carried out in the present investigation and the following conclusions are made:

Incorporating date palm fibres increased plaster modulus of rupture up to one time that for plain plaster at $4 \%$ fibre content.

It has been possible to modify the fracture mode of the gypsum plaster from brittle type to quasi-plastic type by the incorporation of the fibres. This resulted in a greatly improved impact strength, which for a glass content of $10 \%$ was ten times greater than that of u-reinforced plaster. 
Increasing fibre content affected the compressive strength for plaster according to the decrease in density made by both fibre content and the mixing technique.

The impact strength for date palm fibre composite gave the highest improvement and increased to nearly half the strength for fibreglass composites.

\section{References}

1. Ali MA, Grimer FJ (1969) Mechanical properties of glass fibre reinforced gypsum. J Mater Sci 4(5):389
2. Djoudi A, Khenfer MM, Bali A, Kadri EH, Debicki G (2012) Performance of date palm fibres reinforced plaster concrete. Int $\mathbf{J}$ Phys Sci 7(21):2845-2853. http://www.academicjournals.org/jour nal/IJPS/article-abstract/38C34B919211. doi:10.5897/IJPS11.1553. Accessed 25 June 2016

3. Benmansoura N, Agoudjila B, Gherablia A, Karechea A, Boudenneb A (2014) Thermal and mechanical performance of natural mortar reinforced with date palm fibers for use as insulating materials in building. J Energy Build 81:98-104. Journal homepage: http://www.elsevier.com/locate/enbuild. Accessed 25 June 2016

4. Standard Specification for Glass Fiber Reinforced Gypsum Composites-ASTM Committee C11 on Gypsum and Related Building Materials and Systems (2015) ASTM C1355 / C1355M - 96 